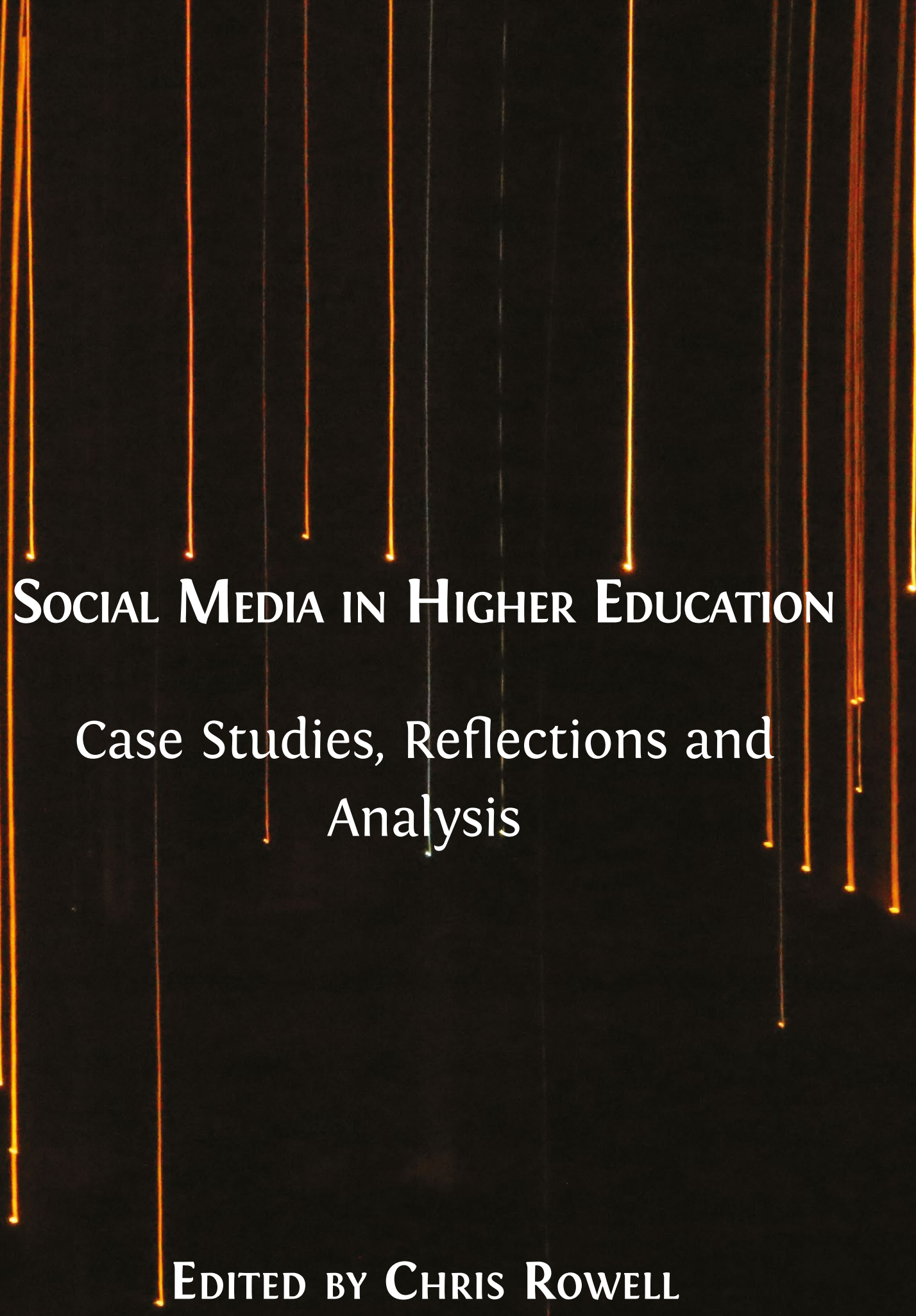




\section{SOCIAL MEDIA \\ IN HIGHER EDUCATION}





\section{Social Media in Higher Education}

Case Studies, Reflections and Analysis

Edited by Chris Rowell

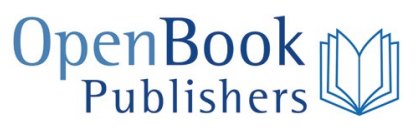




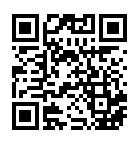

(C) 2019 Chris Rowell. Copyright of individual chapters is maintained by the chapters' authors.

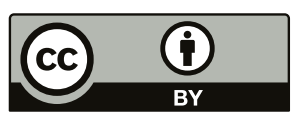

This work is licensed under a Creative Commons Attribution 4.0 International license (CC BY 4.0). This license allows you to share, copy, distribute and transmit the text; to adapt the text and to make commercial use of the text providing attribution is made to the authors (but not in any way that suggests that they endorse you or your use of the work). Attribution should include the following information:

Chris Rowell (ed.), Social Media in Higher Education: Case Studies, Reflections and Analysis. Cambridge, UK: Open Book Publishers, 2019, https://doi.org/10.11647/OBP.0162

In order to access detailed and updated information on the license, please visit, https:// www.openbookpublishers.com/product/994\#copyright

Further details about CC BY licenses are available at, https://creativecommons.org/ licenses/by/4.0/

All external links were active at the time of publication unless otherwise stated and have been archived via the Internet Archive Wayback Machine at https://archive.org/web

Updated digital material and resources associated with this volume are available at https://www.openbookpublishers.com/product/994\#resources

Every effort has been made to identify and contact copyright holders and any omission or error will be corrected if notification is made to the publisher.

ISBN Paperback: 978-1-78374-668-2

ISBN Hardback: 978-1-78374-669-9

ISBN Digital (PDF): 978-1-78374-670-5

ISBN Digital ebook (epub): 978-1-78374-671-2

ISBN Digital ebook (mobi): 978-1-78374-672-9

ISBN XML: 978-1-78374-673-6

DOI: $10.11647 / \mathrm{OBP} .0162$

Cover image: Photo by Francisco Gomes on Unsplash at https://unsplash.com/photos/ kktq8zzmPEo.

Cover design: Anna Gatti. 


\section{Contents}

Acknowledgements ix

Contributors $\quad x i$

Part One Introduction $\quad \mathbf{1}$

1. From a Tweet to a Blog, to a Podcast, to a Book 3 Chris Rowell

2. Social Media in Higher Education - The Podcast 15 Chris Rowell

Part Two Professional Practice 19

3. Developing a Professional Online Presence and Effective 21 Network

Sue Beckingham

4. Re-Engineered Continuing Professional Development and Modelled Use of Cloud Tools and Social Media by Academic Developers

Martin Compton and Timos Almpanis

5. Ten Days of Twitter Mark Warnes

6. Open and Networked Scholarship Suzan Koseoglu

$\begin{array}{ll}\text { Part Three Teaching and Learning } & \mathbf{7 1}\end{array}$

7. Exploring the Use of Social Media in the Higher Education 73 Classroom Alex Avramenko and Chrissi Nerantzi 
8. The Use of Social Media Tools and Their Application to Creative Students Serena Gossain

9. Role of Social Media in Learning: Benefits and

Drawbacks - How Social Presence Theory Explains Conflicting Findings

Paul Kawachi

10. Bursting Out of the Bubble: Social Media, Openness and Higher Education Jennie Blake, Chris Millson and Sam Aston

11. Cambridge Analytica, Facebook, and Understanding Social Media Beyond the Screen

Zoetanya Sujon

\section{Part Four Leadership}

12. Leadership and Social Media Julie Hall

13. Leadership and Social Media: Challenges and Opportunities 141 Donna M. Lanclos and Lawrie Phipps

\section{Part Five Building Networks}

14. Building Cohort Identity through Social Media

David Webster

15. Creating a Sense of Belonging and Connectedness for the Student Arrival Experience in a School of Arts and Humanities

Rachel Challen

16. Joint Reflection on Twitter, Phenomenography and Learning Friendships Margy MacMillan and Chrissi Nerantzi

17. PressEd - Where the Conference Is the Hashtag Pat Lockley and Natalie Lafferty

18. Expertise in Your Ears; Why You Should Jump on the Podcasting Bandwagon

Dave Musson 
19. Etiquette for the Anthropocene Jane Norris

20. Learning to Twalk: An Analysis of a New Learning Environment Andrew Middleton and Alex Spiers

21. Academics' Understanding of Learning Spaces: Attitudes, 237 Practices and Outcomes Explored through the Use of Social Media

Santanu Vasant

Part Seven The Personal Journey

22. Somewhere in Between: My Experience of Twitter as a Tool for Continuous Personal Development

Andy Horton

23. The 'Healthy Academic', Social Media, and a Personal and Professional Journey

Neil Withnell

Glossary

List of Illustrations

Index 



\section{Acknowledgements}

I would like to thank all the authors who have contributed to this book, especially Andy Horton, who helped me with the referencing. The Open Book Publishers team of Alessandra Tosi, Lucy Barnes and Liam Etheridge gave excellent guidance, advice and expertise in bringing this book to completion. Special thanks to Dr Tom Saunders and Martin Bennell for their unique perspectives on social media. The book would not have happened without the support and encouragement of Harriet Gill. And finally, thanks to Rosalie Kerr for being a cool daughter. 


\title{
4. Re-Engineered Continuing Professional Development and Modelled Use of Cloud Tools and Social Media by Academic Developers
}

\author{
\#Intermediate \#Twitter \#CPD
}

Martin Compton and Timos Almpanis

\section{Transforming Lecturer Practice and Mindset}

Academic Developers (a.k.a. Lecturers in Education, Teaching Fellows or Educational, Faculty or Staff Developers) may work in discrete units, within faculties, from within a broader education faculty or closely aligned to Human Resources or Quality departments. Their own values and the organisational structures and culture they work within will likely lead them to exhibit a particular 'orientation' such as 'internal consultant', 'modeller-broker' or 'managerial' (Land, 2001). Despite the growth of the role during the 1990s from a position of obscurity to the norm in most institutions today, the varying orientations and frequent restructuring in many higher education institutions can stifle the role of the Academic Developers and lead to a focus on teams rather than individuals and is rooted in scholarship rather than perceived deficits (Gibbs, 2013). As a new 'tribe' in academia (Bath and Smith, 2004) Academic Developers often work in a delicate environment, balancing the competing demands of senior managers against their own values 
and negotiating the inevitable tensions that exist when working with busy academics (Brew, 2011), especially those that do not see teaching as their first priority. In a complex and varied world there is one thing that unites Academic Developers and that is a commitment to notions of change. One such change is the (often vague) notion that teaching academics should be doing more with technology.

This vagueness is part of the problem, what exactly should lecturers be doing with technology in their teaching? Bayne (2015) argues that the complex interrelationships between technology, society and education are not clearly understood or articulated. It is difficult to simplify what Technology Enhanced Learning (TEL) means and should seek to achieve:

...technology in TEL tends to be black-boxed, under-defined and generally described in instrumental or essentialist terms which either subordinate social practice to technology, or subordinate technology to social practice. (Bayne, 2015)

We are often told that we are or should be in a 'post-digital' age but some higher education providers are still battling with limited Wi-Fi and insufficient computer access (Newman and Beetham, 2017). Likewise, conferences and publications dazzle us with innovative practices that mask the mass of laggards or, at best, late-adopters that perfectly illustrate Rogers' (2003) famous diffusion of innovations model.

We have previously argued (Compton and Almpanis, 2018) that this mixed impression is exacerbated by common models of continuing professional development (CPD) in relation to the use of technology in HE. The CPD is too often standardised and follows a one-size-fits-all model that exhibits the inadequacies of 'transmissive' training rather than the desired 'transformative' development opportunity (Kennedy, 2011).

We nevertheless accept that there is a need to continue to educate academics who teach and those with student-facing roles about the digital capabilities for teaching, learning and assessment, as well as the impact such capabilities could have on their wider professional roles. We argue, though, that many traditional approaches to hastening the pace of change are flawed. Institutional systems (e.g. Virtual Learning Environment, lecture capture) are often conflated in the minds of teachers with all teaching and learning technology. However, we distinguish these from social, collaborative downloadable apps and cloud-based educational and productivity tools designed for education 
or productivity purposes. It is those that we use to enhance our own programmes and use as vehicles to support pedagogy-focussed CPD.

We believe tools that enable collaboration, interaction and enhancement are the perfect vehicle to illuminate the practical potential of better student engagement. In many ways, the general productivity tools serve our goals best. They are designed not with teachers and lecturers in mind, but professionals, or anyone else who wants to interact online. A secondary impact of training people in the use of these tools is that its embeds digital skills into their practice and enhances their employability. When these tools are used alongside social/collaborative tools, they provide lecturers with an opportunity to focus on concepts such as digital professionalism, data protection, and e-safety. Academic developers often have a uniquely pan-institutional vista that affords them the opportunity to witness, harness and disseminate actual applied practices (in contrast to the technical or theoretical) which then, in turn, feed into the practice of others. The following two case studies illustrate how we, as academic developers, use these tools and how we interpret the 'social' in social media through re-engineered CPD and modelled use on the PGCert HE programme.

\section{Case Study 1: Re-engineered CPD}

A common issue is that much institution-wide CPD (from one-off sessions to pan-institutional teaching and learning conferences) is voluntary. In the case of TEL-based CPD, it is the early adopters and not the hard-to-reach that participate. To address these issues we continue to offer a menu of one-off sessions and promote our conferences; but we are also working with key faculty members to engage the harder to reach. For example, we support 'lunch and learn' initiatives, seek invites to whole department or faculty meetings and ensure we are available for faculty-level conferences. Undoubtedly, this is aided and driven by senior management and the culture within which we work, but it can also happen from the bottom up if enthusiastic individuals invite us to such events.

More importantly, we argue that one-size-fits-all, training style CPD sessions are often flawed because they focus on the tool rather than pedagogy and follow a training rather than a discovery format 
(Compton and Almpanis, 2017). Thus, the sessions we offer draw on some core principles:

1. We are explicit about the distinction we make between the institutional systems and CPD on offer. We show value in these systems and make clear the centrality of their role whilst allowing space and acceptance for the frequent gripes about the VLE (navigation, clunkiness, un-intuitiveness) or, for example, lecture capture software (challenge to autonomy, implications for practice).

2. We seek to distinguish our sessions from the common experience of the 'follow the trainer' model and aid participants in embracing the idea that they are not in a stepby-step or 'how to' session.

3. Challenging expectation and mindset is partially achieved by the use of 'quick win' openers that illustrate the philosophy of 'easy, free and fit for purpose' as outlined below. For example a Tweet Wall or 'backchannel' is displayed for in-session interaction and after asking participants to contribute, say, their expectations, they are then challenged to set up their own backchannel for their own teaching (done collaboratively where needed, but usually independently). The opportunities and challenges of using such social interaction methods in their own teaching contexts are then naturally discussed.

Pedagogical needs or the nature of the lecturer-student interaction frames the CPD event, rather than the capabilities of the tools themselves. Thus, in the training session we look at co-creating presentations, focussing on cloud-based presentation tools that have collaborative and social functionality, e.g. Haiku Deck and Prezi and how to organise questions in lectures. A large part of the training session models the use of three or four student response systems and finishes with participants choosing one and creating a resource. We have also designed sessions around the long-established concept of the 'advance organizer' (Ausubel, 1978) to illustrate ways in which relatively simple technologies can be used to ask questions in the classroom and draw students into core concepts through reflection or discussion. 


\title{
Attendees asked 35 questions with a total number of 33 likes
}

$91 \%$ of questions were asked anonymously

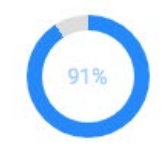

\section{What were the most popular questions?}

\begin{abstract}
(2) Anonymous
6 it 0 ef

Yes, we should make lectures interactive but how can we ensure students are going to interact?
\end{abstract}

1 Anonymous

What if the student doesn't have a device?

1. Anonymous

Keeping large numbers of students engaged is difficult, even with interaction because the quiet ones still escape! How can the quiet ones become engaged?
4 in 0 al
(1) Anonymous
2 it 0 q
Should we go to the pub?
1. Anonymous
2 it 09
How do you get students to sit at the FRONT of the lecture theatre?

Fig. 4.1 Martin Compton, Backchannel ${ }^{1}$ screenshot (2018), CC BY 4.0

1 Backchannel Chat is an app designed to enable teachers to facilitate online discussions about their subject. 
4. As stated above, we are acutely aware of the difficulties many of those in teaching-facing roles have with core technology. Part of the rationale for our approach is to show that there are more accessible entry points and that by using apps and cloud tools as alternatives to built-in VLE functions, for example, the VLE itself can be enhanced. Of course, ease of use is relative so we ensure that there are a range of entry points and that at least one of the ways the pedagogic concept can be addressed with an app or cloud-based tool is very simple. We often highlight the notion that the two core technical skills are 'typing stuff in boxes' and 'copying and pasting web links'.

5. The notion of 'free' is complicated by so-called freemium software or by the implications of an advertising model with adverts appearing alongside resources used. The latter point seems largely immaterial with regard to the ubiquitous YouTube which has normalised this type of advertising, so we simply ensure that participants are alert to limits on freemium tools and the implications of the advertising model.

6. The most important aspect is utility, or a tool's 'fitness for purpose'. To emphasise this point, we refer back to the underpinning pedagogy and encourage participants to recognise their own expertise and contextual pedagogic knowledge. One of the biggest criticisms we have encountered in the past is that academics are unable to connect tools and approaches to their own practice. We pre-empt this challenge by acknowledging it up front, challenging them to find a way to utilise a tool and to share back, at a later date, their experience so that their successes, or even 'magnificent failures', might aid colleagues in or beyond their faculties.

By extending the offer of CPD and by following the principles above, we are seeing a quickening in adoption of social, collaborative and interactive technologies by lecturers and others with teaching responsibilities in the university. In these sessions, we model their use 
by embedding them within the sessions themselves wherever possible, thus providing the opportunity to witness our claims of ease of use. We argue that the best way to challenge cynicism, reluctance or outright fear is to respect the existence of these fears and to host CPD events that are open to them whilst simultaneously challenging them in design and delivery. Our goal is to generate momentum and enthusiasm by addressing head-on some of the obstacles to change that apply not only to use of social media but to all aspects of development in pedagogic practices in our institution.

\section{Case Study 2: PGCert in Higher Education (HE)}

The PGCert in HE is delivered in a blended mode with some face-toface contact and substantial online elements, both synchronous and asynchronous. UK-based participants spend four study days on campus, spread over the duration of the year, whereas international participants are visited by the lecturers twice a year. The rest of the programme takes place online, using a combination of institutionally-supported platforms and cloud-based tools.

Moodle is the backbone of the online component of the course, as all core materials are uploaded and/or linked from it; furthermore, the Moodle discussion forums are used extensively by participants and the course team to discuss weekly topics and peer-review each other's group work in a safe environment. Beyond the walled gardens of the VLE, however, a range of other communication and collaboration tools is used in order to utilise the best tool for each task. This also enables us to demonstrate and model the pedagogically effective use of a range of cloud-based tools and enhance participants' digital capabilities.

This approach begins early in the programme. As part of the induction, participants are encouraged to post a short description about themselves and mention the reasons why they are doing the programme in a Moodle forum, titled 'about me'. They are also encouraged to reply on other participants' posts and comment on common interests. A cloud-based wall is used to collate participants' responses on their initial feelings and experiences of what it is to be a student again.

Additionally, free cloud-based presentation software is used for an ice-breaker activity where participants are asked to create one slide 
each saying something about themselves and asking a question or using their own ice-breaker activity. This way we offer an alternative way of interacting with others on the programme and help to build a community of learners, but also to model some of the ways participants can help their own new students to settle in and build relationships with each other. A screenshot of a slide from this activity is shown in Figure 4.2 below.

\section{Describe yourself as a horse...}

...might be an icebreaker I would do with my equine students....are you a fine, fiery Thoroughbred? Do you work steadily like an Irish cob, or perhaps you're more like a German warmblood, needing patience $\mathbb{E}$ understanding, what colour would you be, \&̋ where do you see yourself? At a show, in a field on Snowdonia, winning Hickstead?

Of course as a an icebreaker on this page this isn't an awful lot of good, so I'll simplify (sounds a bit like the tv program The Cube....).

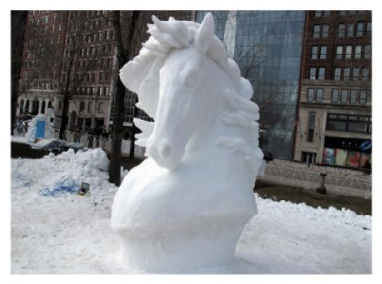

What animal would you be, \& why......?

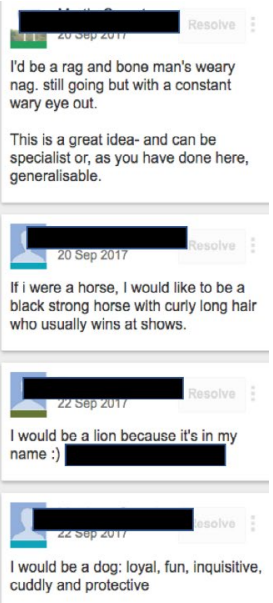

cuddly and protective

Fig. 4.2 Martin Compton, Screenshot of an ice-breaker activity using cloud-based presentation software (2018), CC BY 4.0

Later in the programme, many participants use the same cloud-based presentation software as a basis for their group task on developing a short, narrated presentation on an allocated learning theory.

While asynchronous communication tools offer flexibility regarding the time when a participant can read and respond to a comment, synchronous online communication can further enhance the feeling of belonging in a learning community and motivate participants further during seminar-type activities that take place at predetermined times. During the first module of the PGCert Programme, which covers theory of teaching, learning and assessment, an hourly webinar, which is conducted twice for flexibility in participation, aims to focus participants' learning around a certain topic and promote discussion around it. The webinars are initiated by two course tutors who frame 
the weekly topic and pose relevant questions, encouraging participation and the sharing of views and experiences among the group.

Webinars are recorded and made available from Moodle for revision purposes, but also in order to make sure that any participants unable to attend the recordings are not disadvantaged.

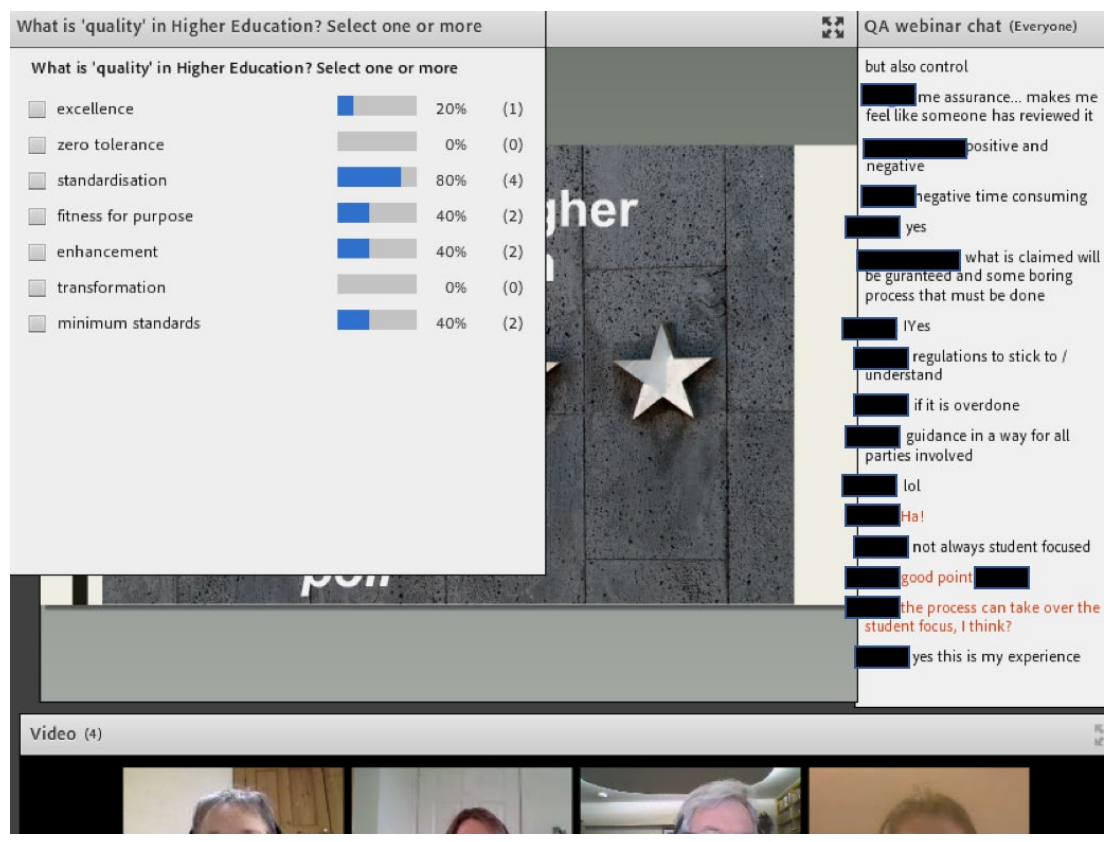

Fig. 4.3 Martin Compton, Screenshot of the web conferencing system in use (2018), CC BY 4.0

The web conferencing system is also used for group tutorials at prearranged times negotiated between the personal tutor and their group; during these, further, tailored advice and support is provided and participants have an opportunity to ask questions and discuss any potential issues with their assignments, or other aspects of the course.

The use of free, real-time online collaboration tools is also encouraged among study groups, so that participants can devise their plan on how to tackle their formative group tasks. Due to the limited licences associated with the main web-conferencing tool that we use, free, synchronous online collaboration tools are promoted; resources and support for 
such online group collaboration is provided by our 'online tutor' of the PGCert programme.

We used a social network curation service that allows for stories/ timelines to be harvested using Twitter and other online media to bring together some tweets from the course leader regarding lesson planning and learning objectives, and it was embedded in a Moodle page. Participants discussed their lesson plans, aims and objectives in the safe environment of the Moodle forum. In this way, participants had access to Twitter content outside of Twitter itself without the need for their own account. It exposed them to the concept of hashtags, curation, and the potential for utilising these tools in their own teaching. We find that Twitter use ranges from 10-20\% in any given group of academics and there is always a lot of prejudice and assumption emanating from those who are non-users. Nevertheless, this use has certainly driven the initial application and the extension of use for teaching and learning purposes amongst the academics we work with.

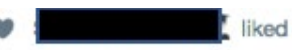

Martin Compton @uogmc · 26 Sep 2017

Check out PGCert in HE / ALTHE at Greenwich smore.com/q0uxv-pgcert-i... \#1286plan

PGCert in HE / ALTHE at Greenwich
Experiences, tips, advice shared by others who have
completed the programmes We have invited previous
participants on our Postgraduate...
smore.com

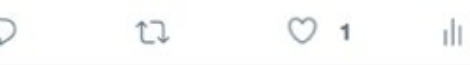

Martin Compton @uogmc · 26 Sep 2017

researchgate.net/post/What_is_T... \#1286plan

What is The Affective Domain and its role in learning?

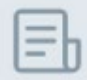

As there are ever increasing pressures on schools and teachers to improve test results, have we overlooked the importance of the affective domain in learning? Can a... researchgate.net

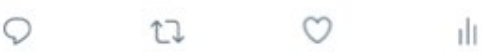


Martin Compton @uogmc · 30 Sep 2016

On the problem of assuming cognitive levels are somehow education level specific vega.jeffco.edu/szak/handouts/... \#1286plan

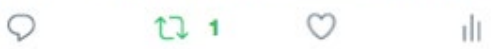

\section{Martin Compton @uogmc · 30 Sep 2016}

Replying to

or see the comments here for a nice range of views \#1286plan researchgate.net/post/What_is_T...

\section{Martin Compton @uogmc · 30 Sep 2016}

if. Replying to

or this extract from Heywood \#1286plan

Fig. 4.4 Martin Compton, Curated content on Twitter which was subsequently re-curated with other online resources and then embedded in the VLE

(2018), CC BY 4.0

Additionally, a Twitter aggregator is used to automatically share relevant, pre-defined content on a daily basis to further aid participants' understanding of the potential of this tool.

\section{The Teaching, Learning and Assessment Daily}

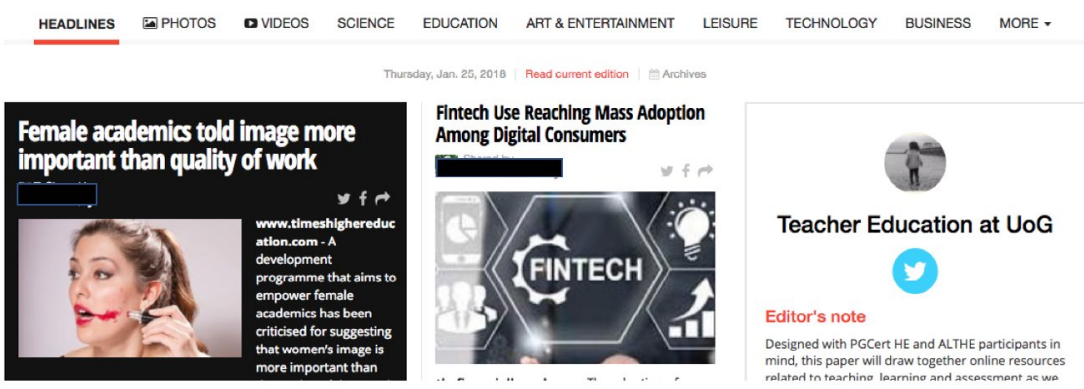

Fig. 4.5 Martin Compton, Screenshot of Twitter content aggregator (2018), CC BY 4.0

An online newsletter was used to collate some programme-related resources regarding peer observations, which is an integral part of the 
programme. The same online newsletter has also been used to outline the way various online tools enhance the course, either by adding interactivity or by creating multimedia content. We are thus using tools that have interactive potential to illustrate and exemplify other tools that do the same. Numerous participants have gone on to use their choice of these tools with their own students.

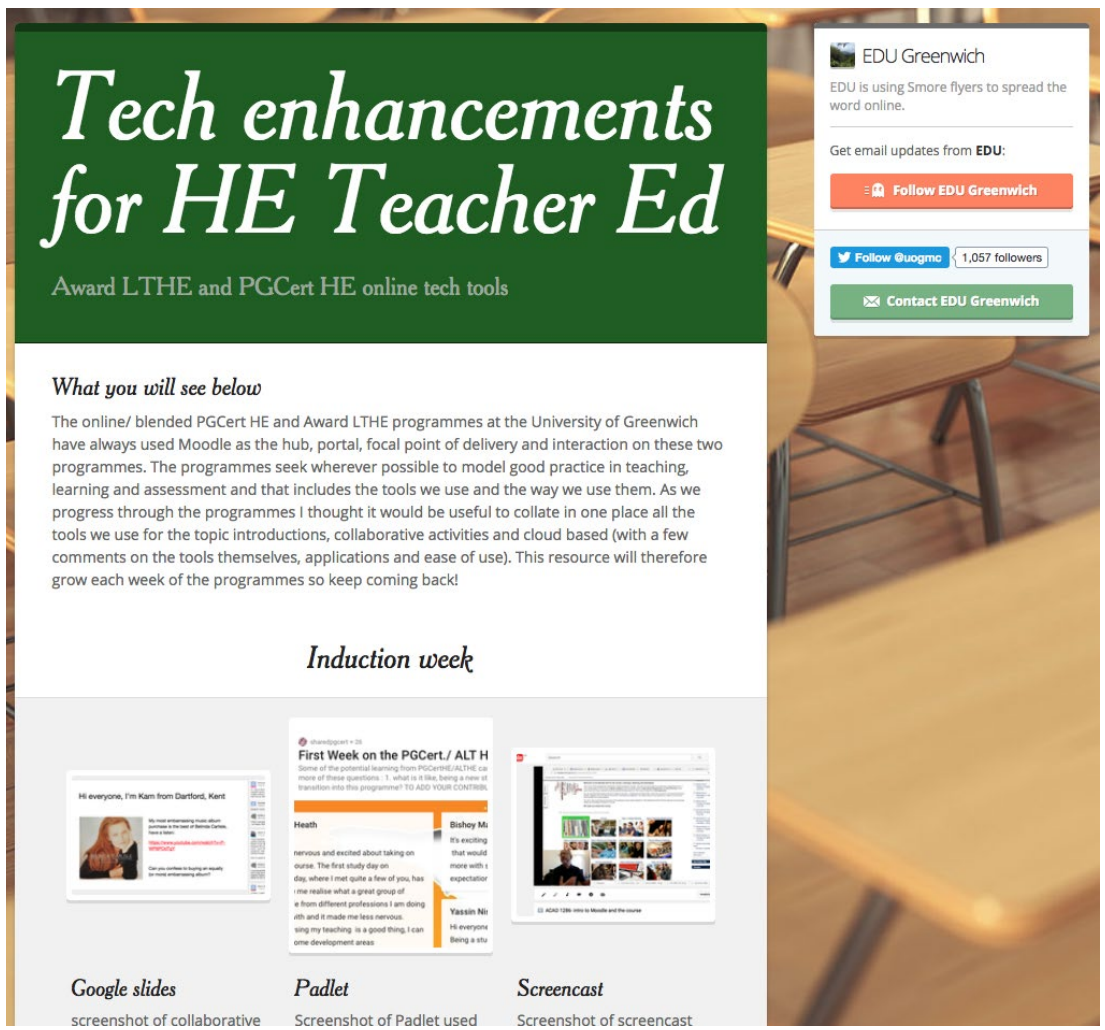

Fig. 4.6 Martin Compton, Newsletter for curation and exemplification with built in social media elements (2018), CC BY 4.0

It is important to note that all of the above tools were used in context to achieve our own teaching and learning goals on the PGCert programme as well as to raise participants' awareness of the possibilities of adopting some of these tools in their own teaching practice. The development of the digital capabilities of participants is also a side-benefit of the course, due not only to its online nature but the fact that TEL is discussed explicitly as one of the topics. We focus on the pedagogical effectiveness 
of TEL by modelling its use, rather than focusing on the technical aspects of the software, as there is often plenty of software solutions that can achieve similar outcomes and the lifecycle of free or freemium software has nowadays been significantly shortened.

\section{Conclusion}

Technology is embedded in all aspects of our lives including work and education and, for better or worse, it is one of the weapons in an academic developer's arsenal; while numerous studies have been published in the field of technology-enhanced learning, there is still some way to go before TEL becomes fully integrated into the student experience. From a staff development perspective, although there are certain minimum digital capabilities required in order for a lecturer to make good use of TEL, an open mind about the possibilities and a willingness to experiment to refresh one's practice are more important. This means that while training and support for institutional platforms may continue to be centralised, sharing knowledge about the pedagogically effective use of various cloud-based applications is very important too. Modified or re-engineered CPD opportunities offered to all staff as well as the Postgraduate Certificate in Higher Education or Postgraduate Certificate in Academic Practice (PGCert in HE/PCAP) course can be the vehicles for that, aiming to move TEL practices beyond the innovation and early-adoption stages.

Whilst it is virtually impossible to empirically measure the impact of the strategies we use, we are confident that the impact can be 'felt' when working with colleagues, and from the unsolicited comments and feedback we've received. A single CPD session in one faculty, for example, led to two attendees embracing one of the promoted social interaction tools. A recent visit to the same faculty's all-staff meeting found that the enthusiasm and willingness of those two relatively new lecturers to share examples in context have led to widespread take-up amongst colleagues who might be seen as 'hard to reach' as far as we, in the academic development team, are concerned. In terms of the PGCert, a 'TEL special issue' of our in-house journal featured contributions from three former participants who have used their experiences on the PGCert to embed social and interactive media in the face-to-face delivery of their 
programmes. They experienced it, they adapted it, they presented it at conferences and subsequently published about it. As part of a relatively small team, we highly value this evident cascading and the willingness to disseminate via both formal and informal mechanisms.

\section{References}

Ausubel, D. P. (1978). 'In defence of advance organizers: A reply to the critics', Review of Educational research, 48:2, pp. 251-57.

Bath, D., and Smith, C. (2004). 'Academic developers: An academic tribe claiming their territory in higher education', International Journal for Academic Development, 9:1, pp. 9-27.

Bayne, S. (2015). 'What's the matter with 'technology-enhanced learning?', Learning, Media and Technology, 40:1, pp. 5-20.

Brew, A. (2011). 'Foreword', in Stefani, L. (ed.) Evaluating the Effectiveness of Academic Development: Principles and Practice, New York: Routledge, pp. 12732.

Compton, M., and Almpanis, T. (2018). ‘One size doesn't fit all: Rethinking approaches to continuing professional development in technology enhanced learning', Compass: Journal of Learning and Teaching, 11:1.

Gibbs, G. (2013). 'Reflections on the changing nature of educational development', International Journal for Academic Development, 18:1, pp. 4-14.

Kennedy, A. (2011). 'Collaborative continuing professional development (CPD) for teachers in Scotland: Aspirations, opportunities and barriers', European Journal of Teacher Education, 34:1, pp. 25-41.

Land, R. (2001). 'Agency, context and change in academic development', International Journal for Academic Development, 6:1, pp. 4-20.

Newman, T and Beetham, H. (2017). Student Digital Experience Tracker 2017: The voices of 22,000 UK Learners. Bristol: Jisc.

Rogers, E. (2003). Diffusion of Innovations. 5th edn. New York: Free Press. 


\section{Glossary}

Backchannel is an online conversation that happens at the same time as a specific event, such as a conference. The backchannel will often happen through Twitter where participants will share comments about the live event. They may also ask or answer specific questions and share related resources or links.

Blog is a website that displays content or posts in a chronological order.

Connectivism is a relatively new theory of how learning takes place in a digital environment. It proposes that learning does not just happen at an individual level but that learning and knowledge can develop outside of the individual through connections between organisations, the Internet, or even data.

Digital badges are indicators of a skill, accomplishment, quality or achievement earned in a learning environment. Badges earned can then be displayed on a social media site or app.

Facebook is the most well know of the social media sites, which enables users to share comments, links (on news or other content) and photos/ videos across the Internet. This shared content can be with just close 'friends' or groups or made publicly available to everyone at a global level.

Facebook Live is a feature of Facebook that enables users to live-stream video recordings. After the live broadcast has been made, a recording will be posted and made permanently available. 
GIF is an acronym for Graphics Interchange Format. They are a file type that can support static and animated images and are often used on Twitter and Facebook.

Github is a website that allows IT developers or groups of programmers to share and manage their code or projects and collaborate with others across the world.

Handle is a person's online identity and is often used as someone's user name of their social media account.

Hashtags are used in social media to identify messages on a specific topic, for example:

\#iacanhazpdf - used on Twitter to request access to academic journal articles which are behind paywalls.

\#LTHEchat - Learning and Teaching in Higher Education Twitter chat.

\#DigPed - Digital pedagogy

\#BYOD4L - 'Bring Your Own Device 4 Learning' course.

\#12AoC - '12 Apps of Christmas' course.

Instagram is a photo and video sharing social media app. Users can share photos and videos which can then be edited using different filters and additional information can be added, such as tags or location information.

LinkedIn is mainly used as a professional networking website and app where employees advertise their vacancies and employees can post their CVs. It allows users to create profiles, post content and make connections with others using the service.

Lurking is being present in an online environment such a chatroom or Twitter chat but not participating in any interactions.

Meme refers to an image or video with a short piece of text, often with a humorous content, that is copied and distributed on social media platforms. 
Medium is a website that publishes a wide variety of content, from personal blog posts to professional publications.

Moodle is an open-source virtual learning environment (VLE) used by education institutions to host content, deliver courses and facilitate blended and distance education.

MOOC is a Massive Open Online Course. These courses are fully online and have unlimited enrolment so they often have very large numbers of students on the course.

Open Education is the general outlook that educational resources and knowledge should be made freely accessible to all, and that we should aim to eliminate any barriers to achieve this goal. Promoting collaboration is a key feature of open education.

Phenomenography is a qualitative research methodology, usually based on interviews that aims to investigate the way people think or experience something. It emphasises the interviewee's refection and description of experiences.

Pinterest is a visual social media service that allows users to share videos and images. Images are called 'pin's and they are put onto 'pinboards' which can be customised according to different themes and then followed by others.

Podcasts are a series of digital audio recordings that listeners can download or streamed to their device.

Snapchat is an app for sharing photos, videos and messages. Its distinctive feature is that once the message has been received via Snapchat it is automatically deleted.

Tag is a keyword or phrase added to a social media post with the purpose of relating it to a category or collection.

Twalk is a structured walk augmented by the use of social media (usually Twitter). Participants will walk around a specified route, discussing a nominated topic(s) and use Twitter to enhance the discussions or debates. 
Tweet Wall is an app or platform that displays tweets which include a specified hashtag. They are often displayed on a large screen within a populated area, such as a conference or classroom.

Twitter is a service that enables its users to publish short messages (up to 280 characters) called tweets. These tweets enable users to communicate with one another, share links/photos/videos and publicise events.

Twitter chat (or tweetchat) is usually a live event focused around a specific topic. The chat is usually based on a single hashtag.

Visitors and Residents is a simple way of visually plotting users' engagement in online environments. It maps their engagement with online tools on a continuum from visitors to residents depending upon their level of activity.

VLE is a virtual learning environment, it is an online space where learning materials and teaching/learning tools are hosted. Examples include, Moodle, Blackboard and Canvas.

WhatsApp is a messenger app, similar to a text messenger service, which allows the user to send messages, audio, images and videos. It also has features like group chatting and voice messaging.

WordPress is open source software that is often used as a blog. 


\section{List of Illustrations}

\section{Chapter 3}

3.1 Sue Beckingham, Affordances within LinkedIn (2018), CC BY 4.0

3.2 Tanmay Vora, Five Elements of Working Out Loud (2017), http:// qaspire.com/2017/01/26/5-elements-of-working-out-loud-byjohnstepper/

3.3 Sue Beckingham, Developing a professional online presence (2018), CC BY 4.0

3.4 Sue Beckingham, Developing an online presence: contributing factors (2018), CC BY 4.0

\section{Chapter 4}

4.1 Martin Compton, Backchannel screenshot (2018), CC BY 4.0

4.2 Martin Compton, Screenshot of an ice-breaker activity using cloud-based presentation software (2018), CC BY 4.0

4.3 Martin Compton, Screenshot of the web conferencing system in use (2018), CC BY 4.0

4.4 Martin Compton, Curated content on Twitter which was subsequently re-curated with other online resources and then embedded in the VLE (2018), CC BY 4.0

4.5 Martin Compton, Screenshot of Twitter content aggregator (2018), CC BY 4.0

4.6 Martin Compton, Newsletter for curation and exemplification with built in social media elements (2018), CC BY 4.0 


\section{Chapter 5}

5.1 Mark Warnes, ARU10DoT blog posts: types of subscription and number of followers (2018), CC BY 4.0

\section{Chapter 6}

6.1 Susan Koseoglu, \#HEdigID Twitter chat: a series of chats

focusing on Networked, Digital Life in HE (2018), CC BY 4.0, https://twitter.com/laurapasquini/status/956978197438091264

6.2 Susan Koseoglu, Prof. Kalwant Bhopal's reaction to an article published by The Guardian (2018), CC BY 4.0, https://twitter. com/KalwantBhopal/status/956923189887754241

\section{Chapter 8}

8.1 Serena Gossain, Screenshot of LCC Bad Instagram page (2018), $\quad 88$ CC BY 4.0

8.2 Serena Gossain, Screenshot of LCC Ads Pinterest board (2018), CC BY 4.0

\section{Chapter 9}

9.1 Paul Kawachi, The four stages of the Transactional Distance 99 Model (2018), CC BY 4.0

9.2 Paul Kawachi, The position of social presence in the educative 101 process (2018), CC BY 4.0

9.3 Paul Kawachi, The essential kinds of presence in Online 103 Education (2018), CC BY 4.0

\section{Chapter 11}

11.1 Zoetanya Sujon, Screenshot highlighting Facebook's 'Terms' (2018), CC BY 4.0 
11.2 Zoetanya Sujon, Locating the activity log on your Facebook account (2018), CC BY 4.0

11.3 Zoetanya Sujon, One event from a Facebook activity log, highlighting visibility settings (2018), CC BY 4.0

\section{Chapter 13}

13.1 Lawrie Phipps and Donna Lanclos, Mapping triangle (2018), CC BY 4.0. The interior of the triangle is where people map the practices that are bounded by their institution and the work they do in institutional digital platforms and places. The exterior of the triangle is where they can map everything else - what they do that is not bounded by the institution. This can be their personal lives, or their work that does not take place in official channels, but rather on the open web, in self-hosted or commercial platforms.

13.2 Lawrie Phipps and Donna Lanclos, Triangle map with annotations (2018). Image used with permission of participant, CC BY 4.0

\section{Chapter 15}

15.1 Rachel Challen, Written representation of the storyboard 167 (2018), CC BY 4.0

15.2 Rachel Challen, Photo of (L-R) Dr Sharon Ouditt, Head of Department, English, Media and Creative Cultures; Dr Karen Randell, Deputy Dean; and Dr Nicholas Morton, Senior Lecturer in History (2018), CC BY 4.0

\section{Chapter 17}

17.1 Pat Lockley, Tweeters (2018), CC BY 4.0 185

17.2 Pat Lockley, Number of Tweets (2018), CC BY 4.0 185

17.3 Pat Lockley, Average number of replies per Tweet (2018), CC 186 BY 4.0

17.4 Pat Lockley, Average number of retweets (2018), CC BY 4.0 186

17.5 Pat Lockley, Average number of favourites (2018), CC BY $4.0 \quad 186$ 
17.6 Pat Lockley, \#pressedcon18 user data (2018), CC BY $4.0 \quad 188$

17.7 Pat Lockley, Number of times \#PressEd18 tweets were seen 189 (2018), CC BY 4.0

17.8 Pat Lockley, Number of impressions (2018), CC BY 4.0

17.9 Pat Lockley, Retweets (2018), CC BY $4.0 \quad 191$

17.10 Pat Lockley, Replies (2018), CC BY 4.0 191

17.11 Pat Lockley, Likes (2018), CC BY 4.0 191

17.12 Pat Lockley, Overall \#PressedConf18 impressions (2018), CC 192 BY 4.0

17.13 Pat Lockley, Followers and impressions (2018), CC BY 4.0 192

17.14 Pat Lockley, Threaded tweets (2018), CC BY 4.0 193

\section{Chapter 19}

19.1 Jane Norris, Cards and badges and Instagram page, https:// 214 www.instagram.com/optimism.janenorris/ (2018), CC BY 4.0

19.2 Jane Norris, Other badges (2018), CC BY 4.0

\section{Chapter 21}

21.1 Radcliffe, A Pedagogy-Space-Technology framework for designing and evaluating learning spaces (2008), http:// openarc.co.za/sites/default/files/Attachments/UQ\%20Next\%20 Generation\%20Book.pdf

21.2 Kolb, Learning Cycle (1984) 


\section{Index}

\#Advanced 6, 183

\#Beginner 6, 21, 73, 83, 107, 117, 133, 153, 161, 199, 237, 251, 261

\#Intermediate 6-7, 35, 49, 61, 95, 141, $171,211,223$

Academia.edu 26

Academic Developers 35-36

Amazon 119, 145

Amazon Mechanical Turk 119

Android 201

Anthropocene 11, 17, 212, 217

Apple 200-201, 203

AudioBoom 26

backchannel 38, 184, 194, 251, 253-254, 256, 269

Badge Alliance 54

BAME 158

Blackboard 75, 77, 109, 272

blog, blogging 3, 6, 9-10, 12, 27, 29, $31,50-55,57-58,62,65,109-110$, $114,148,155-158,200,252$, 271-272

Blogger 26

Bluetooth 201

Brexit 120, 204

Bring Your Own Device for Learning (BYOD4L) 32, 223-224, 234, 270

Cambridge Analytica 9, 16, 117-121, 127-128

Canada, Canadian 171, 204, 229

Chat 98

Cognitive learning approach 85-86, 90
Cognitive Presence 100-102

Connectivism 87, 91, 98, 194, 269

Constructivism 85-86, 90-91

Continuing Professional

Development (CPD) 7, 15, 21, 35-38, 40-41, 47, 51, 56, 58, 225, $237,245-246,251-252$

Conversation Theory 98

Coursera 55

Creative Commons 8, 58

Credly 54

Digital Badges 50, 52-55, 57-58

digital footprint 22, 26, 265

digital natives 117-119, 134, 143, 154

Diigo 26

Direct Message (DM) 6, 54

edX 55

European Union (EU) 55

Explorer 134

Facebook 4-5, 9-10, 16, 24-26, 49, 51, $55,61,67,73,76-77,79,81,83-84$, 95-98, 104-105, 117-128, 145, 153, 156-158, 161-165, 168-169, 175, 179, 215-217, 238, 257, 261, 263-265, 269-270

Facebook Live 10, 161-164, 168-169, 269

Flickr 26, 31, 156

FutureLearn 55

Gestalt psychology 85 
Google 23-24, 30, 51, 114, 145, 200

Google+ 51

habitus 217

Haiku Deck 38

hashtag $6-7,51,53,62,87,110,136$, 176, 183-185, 187, 192-193, 214, 227, 231-232, 238, 243, 252-256, 272

higher education (HE) 3-5, 7-9, 11-12, 16, 25, 29, 35-37, 41, 47, 49, $61,63,65,67,73-75,77-78,81$, 107-108, 111-112, 114, 117-118, 127, 134-135, 137-138, 149, 153-154, 162, 169, 200, 202-203, 207, 212, 239-242, 244, 246, 251-252, 255, 258, 270

Hootsuite 243

Human Resources (HR) 35, 51

identity $4,7,10,12,21,23-24,26-27$, 31, 84, 103-104, 110, 112, 141-142, 144-146, 154-155, 157-158, 231, $239,252,257-258,262,265,270$

Instagram $6,8,11,26,49,73,83-84$, 86-92, 98, 156-158, 211, 213-217, 221, 223, 270

Instant Messenger 215

Institutional Presence 100

iPhone 201

iPod 200-201, 203

iTunes 201, 208

iTunesU 203

Jisc 9, 49, 57, 141-143

Kogan, Aleksander 119, 128

Kolb's Learning Cycle 243

Koum, Jan 120

Learner Presence 100-101

Learning Resources 256

Learning Spaces 237, 244

Learning Technology in Higher Education (LTHE) 255

Likert scale 75

LinkedIn 21, 23, 25-27, 29, 31, 51, 55, $73,168,257,261,264,270$
Livejournal 252

London 8, 58, 83, 155, 212, 229, 241, 255

LTHEchat 12, 31-32, 183, 241, 255, 270

Medium 5, 9, 107, 110-115, 271

Mendeley 26

Mentimeter 78, 80-81

Mention.com 30

microblogging 4, 26

MobileFirst platform 128

MOOC (Massive Open Online Course) 50, 55, 112, 256, 271

Moodle 41, 43-44, 157-158, 271-272

Mozilla 54

networked participatory scholarship 7, 26, 112

Network Publics 61

open and networked scholarship 8, $62-63,68$

Open Badges.me 54

Open Badges.org 54

open education $63,109,112,271$

Open Knowledge 107

open scholarship $62,65,68,112$

Personal Learning Networks (PLN) 8,234

PGCert 37, 41-42, 44, 46-47, 242

phenomenography $10,17,172-175$, 177-178, 180-181

Pinterest 8, 73, 79, 83-86, 88-90, 92, 216,271

podcast, podcasting $5-6,11,15,17$, 199-209

PowerPoint 57

Prezi 38

ResearchGate 26

RSS feed 201

Safari 134

Sci-hub 112

Skype 61, 157, 178

SlideShare 27 
Slow Learner 114

smartphones 8, 73-81, 84, 153, 168, 201-202

Snapchat 5, 49, 83-84, 211, 215, 217, 271

social bookmarking 26

social media 3-12, 15-16, 18, 21-23, 26, 30-32, 37, 41, 49, 51, 54, 57-58, $61,63,66-67,73-79,81,83-84$, 86-87, 91-93, 95-98, 102-106, 111-112, 114-115, 117-121, 127-128, 133-139, 141-143, 148-149, 153-159, 161, 163, 169, 171, 173-174, 180, 183, 199, 213, 215-218, 221, 223-224, 226, 229, 231, 234, 238-239, 241-242, 244, 246, 251-255, 257, 261-266, 269-271

Social Media for Learning (SM4L) 49, 224,234

social networks 26, 65-66, 76, 110, 121

Social Presence 95-98, 100-102, 104, 106

Social Presence Theory 96, 98, 100, 104 Socrative $78,80-81$

SoundCloud 26

surveillance capitalism 9, 118, 120

SurveyMonkey 54, 57

Teaching Excellence Framework (TEF) 241, 244

Teaching Presence 100

Technology Enhanced Learning (TEL) $36-37,46-47,55$

timeline 56, 124-126, 188, 258

Transactional Distance Model 96, 98, 100, 103

Transactional Distance Theory 98

Transactional Presence 100, 102

Trump, Donald 120, 204

Tumblr 26

Twalk, Twalking 11-12, 18, 223-224, 226-234, 237-245, 271

tweet $3,6,10-12,24,31,38,44,50$, 52-54, 56, 135-136, 157, 175-176, 184-190, 192-193, 227, 231, 238, 241, 243, 253-254, 256, 258, 272 tweetchat 226-229, 237-239, 242-246, 255,272

TweetDeck 54, 243

Tweet Wall 38, 272

Twitter 5-8, 10-12, 17-18, 21, 24, 26-27, 29, 31-32, 35, 44-45, 49-57, 61-63, 67, 81, 84, 98, 109-111, 133, 135-139, 141, 149, 156-158, 168, 171, 174-177, 179-180, 183-188, 190, 193-194, 211, 216-217, 223, 227-228, 231-232, 237-239, 242-243, 251-258, 261, 265, 269-272

Twitter chat $61,63,183,223,227,252$, 270,272

Twitter conference 10, 183-186, 193-194

Twittersphere 172

Vancouver 136, 226

Vimeo 26

Virtual Learning Environment (VLE) 36, 38, 40-41, 107, 109, 157, 271-272

Virtually Connecting 183

Visitors and Residents 143, 272

WhatsApp 5, 117, 120, 215, 263, 272

Wi-Fi 36, 167-168, 232

Wikipedia 183

women and social media 133, 138, 144,158

WordPress 11, 26, 31, 50-52, 57, 110, $153,157,168,183,272$

working out loud 27

YouTube 5, 26, 31, 40, 49, 61, 84, 238, 261

Zuckerberg, Mark 119-120 



\section{This book need not end here...}

\section{Share}

All our books - including the one you have just read - are free to access online so that students, researchers and members of the public who can't afford a printed edition will have access to the same ideas. This title will be accessed online by hundreds of readers each month across the globe: why not share the link so that someone you know is one of them?

This book and additional content is available at: https://doi.org/10.11647/OBP.0162

\section{Customise}

Personalise your copy of this book or design new books using OBP and thirdparty material. Take chapters or whole books from our published list and make a special edition, a new anthology or an illuminating coursepack. Each customised edition will be produced as a paperback and a downloadable PDF. Find out more at:

https://www.openbookpublishers.com/section/59/1

\section{Like Open Book Publishers $f$}

Follow@OpenBookPublish

Read more at the Open Book Publishers BLOG 


\section{You may also be interested in:}

\section{Open Education}

International Perspectives in Higher Education

Patrick Blessinger and TJ Bliss (eds.)

https://doi.org/10.11647/OBP.0103
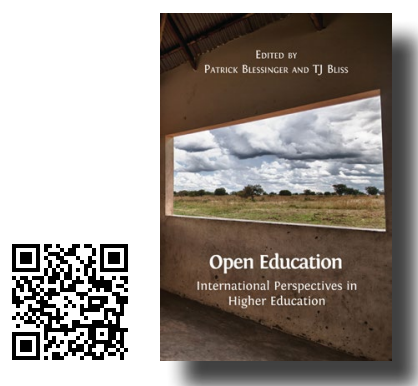

\section{Digital Humanities Pedagogy}

Practices, Principles and Politics

Brett D. Hirsch (ed.)

https://doi.org/10.11647/OBP.0024

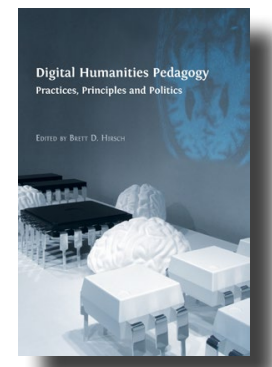

Delivering on the Promise of Democracy

Visual Case Studies in Educational Equity and Transformation

Sukhwant Jhaj

https://doi.org/10.11647/OBP.0157

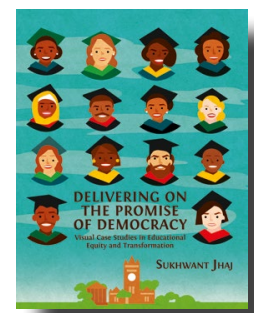




\section{Social Media in Higher Education}

\section{Case Studies, Reflections and Analysis}

\section{Edited by Chris Rowell}

An experiment in form and content, its aim is to be a guide and map of some of the opportunities to develop more open and networked practices while navigating the potential downsides of social media, including perceived loss of privacy and amplification of disadvantage and abuse. It is an excellent and accessible starting point for, as well as route to, a deeper understanding and a more sophisticated use of social media.

-Prof. Shân Wareing, Deputy Vice-Chancellor, London South Bank University

How does social media affect working life in Higher Education? How are universities harnessing its power to aid student learning? This innovative collection brings together academics and those working in professional services to examine these questions and more. The diverse and expert contributors analyse the many ways social media can be used to enhance teaching and learning, research, professional practice, leadership, networking and career development. The impact of social media is evaluated critically, with an eye both to the benefits and the problems of using these new forms of digital communication.

This is the first volume to give such detailed attention to this area of high interest. Its innovative approach extends to its creation, with contributors found via their presence on Twitter. The short and impactful chapters are accessible while retaining an academic focus through their application of relevant learning theories and educational context.

Social Media and Higher Education is essential reading for any professional working in higher education, including lecturers teaching education courses. It is also significant for researchers looking at more recent developments in the field and what it means to work in a modern higher education environment.

As with all Open Book publications, this entire book is available to read for free on the publisher's website. Printed and digital editions, together with supplementary digital material, can also be found at www.openbookpublishers.com

Cover image: Photo by Francisco Gomes on Unsplash at https://unsplash.com/photos/ kktq8zzmPEo. Cover design: Anna Gatti

ebook

ebook and OA editions also available

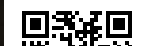

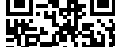

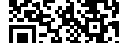

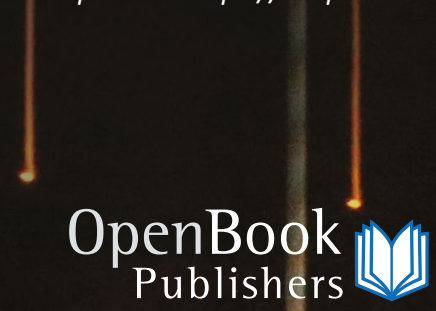

